\title{
Promoting Behavioral Support for Change: A Conservation of Resources Theory Perspective
}

\author{
Farhan Mehboob*1, Noraini Othman² \\ 1,2 School of Business Management, Universiti Utara Malaysia, Malaysia \\ * Corresponding author: farhan.mehboob9@gmail.com
}

Article History

Received 2020-08-29

Revised 2020-09-06

Accepted 2020-09-23

Published 2020-10-01

\section{Keywords}

Organizational Change

Perceived Management Support

Change-efficacy

Behavioral Support for Change

\section{How to cite?}

Mebboob, F., \& Othman, N. (2020).

Promoting Behavioral Support for Change:

A Conservation of Resources Theory

Perspective SEISENSE Journal of

Management, 3(6), 1-13. doi:

$10.33215 /$ sjom.v3i6.448
Purpose- Individuals' support for change is a critical success factor to implement change effectively. Therefore, identifying the possible antecedent and mechanism, leading to behavioral support towards change, is necessary. The study aims to unfold this avenue of research empirically by examining the role of both person and context factors in promoting behavioral support for change.

Design/Methodology- Data was collected from 292 academic staff of six public sector universities located in Pakistan via crosssectional mean. A self-reported questionnaire was used to collect responses from the desired population.

Findings- Results revealed a positive impact of perceived management support on academic staff's behavioral support for change. Moreover, change-efficacy also provides a statistically significant intervening mechanism to translate the effect of perceived management support on both dimensions of behavioral support to change such as compliance and championing behavior

Practical Implications- The research offers useful insights for top university officials to build support for change by providing needed support and resources; make academic staff capable of executing the change-related tasks into viable actions meritoriously. 


\section{Introduction}

Ongoing and continuous change has substantially reshaped the nature and scope of tasks and organizations (Cascio \& Aguinis, 2008). Breakthrough in the areas of information and technology has challenged the survival and existence of many of the organizations across the globe (Tomprou, Nikolaou, \& Vakola, 2012). The globalization and competitive pressure; rapidly evolving choices for communities, societies, and customers; and the growing complexity in social and technical ties have been identified as one of those potential factors that have been pushing organizations to continually adapt themselves to the changing dynamics (Schreyögg \& Sydow, 2010). Thereby, for organizations to survive and flourish, they have to enhance their resilience toward these socio-economic fluctuations (Burke, 2002). Consequently, organizations have to take frequent initiatives to bring about change in important organizational constituents (Amis \& Aïssaoui, 2013). The nature and scope of this change could be diverse and constituted of multiphase interventions such as downsizing (Day, Armenakis, Feild, \& Norris, 2012), mergers (Kavanagh \& Ashkanasy, 2006), restructuring, and strategic change (Wanberg \& Banas, 2000), to quality improvement initiatives (Coyle-Shapiro, 1999). This diversity in change makes it difficult to interpret its ultimate outcomes (Stouten, Rousseau, \& De Cremer, 2018) and hence mainly rely on subjective assessment and evaluation (Hiatt, 2006).

In response to the novel ways of doing businesses and providing services through structural and process transformations; employees' response towards these change initiatives has been becoming increasingly critical to sustain and make change more of a successful venture ((Bouckenooghe, M. Schwarz, \& Minbashian, 2015; Oreg, Bartunek, Lee, \& Do, 2018; Oreg, Vakola, \& Armenakis, 2011; van den Heuvel, Demerouti, \& Bakker, 2014). There is a consensus prevailing all over the change management literature and practices that employees' positive reaction and support is key to the success of organizational change (Bakari, Hunjra, \& Niazi, 2017; Shin, Taylor, \& Seo, 2012; Zhao, Seibert, Taylor, Lee, \& Lam, 2016). For instance, past studies have indicated that one of the major causes of massive failure rates of about every two-third of the change initiatives has been due to employees lack support toward change (Cinite, Duxbury, \& Higgins, 2009; Jansson, 2013; Michel, Todnem, \& Burnes, 2013).

Given the role of individuals' support as a critical success factor to bring about change, identifying ways to enact such change support related response has been positing a severe challenge. About address the subsequent issue, the current study examines the potential intervening mechanism through which the change supportive behavioral response likely to be manifested and lead organizations toward better adaptation to the change. The study, in particular, aims to uncover the role of context and personal factors in facilitating one's behavioral support to change. To capture the innate complexities of organizational change and its implications, consideration of both personal and contextual factors is essential to capture the essence of organizational change and its practical implementation to the context. Although past literature on organizational change has elicited both personal and contextual factors as fundamental to successfully bring about change (Fugate \& Soenen, 2018; Oreg et al., 2018, 2011), however, rarely have been explored yet about their simultaneous examination in the same study (Fugate \& Soenen, 2018).

To assist in advancing the suggestions, the current study addresses this limitation by focusing on the corresponding factors and their underlying relationship pattern in response to the organizational change. Specifically, the study sought to examine the intervening role of self-efficacy (person factor) in the relationship between the perceived management support (context factor) and individuals' behavioral support for change (support factor). The study argues that perceived management support to behavioral support for change relationship would be mediated and effectively translated when the individuals found high at their efficacy level. In brief, perceived management support likely to induce the efficacy level among individuals, which may lead to subsequent change-oriented support behaviors. 


\section{Literature Review}

\section{Impact of Perceived Management Support on Behavioral Support for Change}

Prior research on organizational change opined that individuals' perception and beliefs towards change result in behaviors that are persistent, effortful, and focused in their attempts to support and facilitate the effective implementation of the change initiatives (Haffar, Al-Karaghouli, Irani, Djebarni, \& Gbadamosi, 2019; Iqbal \& Asrar-ul-Haq, 2018; Oreg et al., 2018, 2011; Rafferty, Jimmieson, \& Armenakis, 2013). Taken account of the behavioral perspective to change, Herscovitch and Meyer (2002) distinguished these behavioral manifestations about their level of activation and support towards change either via passive or active orientation, namely compliance and championing behavior. According to them, the minimally acceptable level of support that can be carried out during the change is 'compliance' with the statutory instructions, rules, and directions because of the change under consideration. It is "demonstrating minimum support for a change by going along with the change, but doing so reluctantly" (p. 478). Compliance "occurs when the target person carries out the requested action but is apathetic about it rather than enthusiastic, makes only a minimal or average effort, and does not show any initiative" (Falbe \& Yukl, 1992, p. 639). Championing behavior, on the other hand, involves "demonstrating extreme enthusiasm for a change by going above and beyond what is formally required to ensure the success of the change and promoting the change to others" (p. 478). Championing "occurs when a target person agrees internally with an action or decision, is enthusiastic about it, and is likely to exercise initiative and demonstrate unusual effort and persistence to carry out the request successfully" (Falbe \& Yukl, 1992, p. 640). Discretionary efforts, therefore, are essentially practical and conceptual means of distinguishing between employee compliance and championing behavior. Accordingly, identifying relative antecedent and their relationship with these forms of support behaviors is valuable for researchers and practitioners. The subsequent significance of behavioral support for change combined with paucity of empirical research examining the bifolded perspectives to support behaviors provide a core impetus to conduct this study.

Referring to the importance of contextual factors to successfully teach the support for change, the study aims to examine the role of perceived management support as a potential contextual antecedent to induce a positive stimulus among individuals towards change. It has generally been viewed as an essential context attribute in successfully implementing organizational change (Armenakis \& Bedeian, 1999; Neves, 2009). Perceive management support refers to providing support from organizational leaders, including formal and informal leaders (Armenakis \& Fredenberger, 1997), opinion leaders, or change agents (Armenakis, Bernerth, Pitts, \& Walker, 2007). Jimmieson, Terry and Callan, (2004) argued that "one of the managerial challenges facing organizations is the effective implementation of organizational change programs that minimize feelings of uncertainty and associated threat" (p. 11). This highlights how top management is primarily responsible for influencing employee perceptions, expectations, appraisals, and behavioral reactions to implement change (Rafferty \& Restubog, 2017) successfully. Rafferty and colleagues (2013) coincide with 'internal context enablers,' which often elicits change management processes that foster individuals' vertical coordination with the higher-ups and stimulate positive work behaviors. Vakola (2014) argued that employees who perceive their managers are supportive, inspiring and trustworthy and openly communicate the change are more likely to develop a positive image regarding the change that ultimately lead employees to demonstrate their support toward change.

A review of past research reveals that perceived management support serves as a central function in enacting employee acceptance to change. For instance, while examining the role of supportive leadership as a predictor of employee commitment to change, Sharma et al. (2018) found a strong positive association between each other. Likewise, Rafferty and Minbashian (2019), in a recent study, observed that perceived management support significantly leads to employees' change supportive behaviors. A study by Bakari et al. (2017) also indicated perceived management support as an antecedent to one's commitment to change. In brief, when 
employees report that their leaders and superiors provide adequate support necessary to implement change, their perceived extent of available opportunities to engage in supportive behaviors enhances thus resulting in more supportive behavior about the corresponding organizational change. Because of the theoretical rationale and empirical pieces of evidence, the study thereby hypothesizing that perceived management support is related to both compliance and championing dimensions of individuals' support toward change.

H1a: Perceived management support is positively related to compliance behavior

H1b: Perceived management support is positively related to championing behavior

\section{Mediating Role of Change-related Self-Efficacy in the Relationship between Perceived Management Support and Dimensions of Behavioral Support for Change}

Drawing on social cognitive theory, self-efficacy is the core in determining whether an individual can successfully translate the reality in ways he or she intends to (Ng \& Lucianetti, 2016). Self-efficacy comprises confidence in one's own capacity to coordinate and execute the course of actions required to manage the prospective circumstances (Bandura, 1995). It represents one's perceived conviction, competence, and optimistic assessment that he or she can successfully execute the action required to reach the desired end (Hughes, Galbraith, \& White, 2011). Holt, Armenakis, Feild, \& Harris (2007) defined efficacy belief as to the "extent to which one feels that he or she has or does not have the skills and is or is not able to execute the tasks and activities that are associated with the implementation of the prospective change" (p. 238). According to them, individuals high in efficacy belief found themselves more capable of performing the tasks successfully once the change is being made.

Keeping in view, past research noted that one's self-efficacy is mainly instrumental for their ability to accomplish their job requirement in the presence of adverse or demanding situations such as during the organizational change (e.g., Bakari et al., 2017; Rafferty \& Minbashian, 2019). This is in line with the principles of conservations of resources theory (COR), whereby it argues that individuals' extent of self-efficacy reflects a critical personal resource that fosters their work engagement in performance-enhancement activities (Hobfoll, 2001; Tims, Bakker, \& Derks, 2014). The COR theory postulates that individuals are motivated to protect or enhance their value the most (Hobfoll, 1989). The individuals with more resources are generally more capable of protecting or enhancing their valuable resources by investing more into those resources; whereas those who possess fewer resources are more vulnerable to the loss of such resources (Hobfoll, Halbesleben, Neveu, \& Westman, 2018; Strauss \& Parker, 2018). The likelihood that employees can generate or accumulate additional resources not only depends on the resources embedded in their working context, such as perceived management support (Zhou, Martinez, Ferreira, \& Rodrigues, 2016) but also on their characteristics such as self-efficacy. In this regard, organizations can benefit immensely by leveraging employees' perceptions towards management support and self-efficacy resource to neutralize the resource loss or depleting effect of organizational change. In particular, COR theorizes that possession of such resources generates a motivating effect because these resources help in to spur the generation or accumulation of additional resources (De Clercq \& Belausteguigoitia, 2017; Hobfoll, 1989) and contribute positively to achieve job-related goals (Alessandri, Borgogni, \& Truxillo, 2015; Miraglia, Alessandri, \& Borgogni, 2015).

According to the COR theory, these resources, such as perceived management support and self-efficacy, have an essential role in organizational change, considering change is a stressful and demanding process for individuals (Herscovitch \& Meyer, 2002; Huy, 1999). As a result, they need more resources than usual to cope with this demand and develop a positive reaction towards change initiatives (Shin et al., 2012). Moreover, resources employee receives form the top management during organizational change; help them to prepare themselves to cope with the subsequent job demands and shows their needed support about the organizational 
change (Bayraktar, 2019). It suggests that management can provide a valuable resource in terms of support that may further enhance employees' belief regarding their self-efficacy to implement the change successfully.

Consistent with the rationale highlighting the significance of self-efficacy in contributing to the employees' accomplishment of performance objectives, prior studies have also supported the role of efficacy in bringing about organizational change (e.g., Amiot, Terry, Jimmieson, \& Callan, 2006; Jimmieson et al., 2004). Moreover, recent research has also found a positive role of efficacy in determining the change-related outcomes (Bakari et al., 2017; Haffar, Al-Karaghouli, \& Ghoneim, 2014; Haffar et al., 2019; Rafferty \& Minbashian, 2019). However, the role of change -efficacy as a potential mediating mechanism to translate the direct impact of perceived management support on change supportive behavior has been least attended in past literature. The study thereby hypothesized change-efficacy as a mediator in the relationship between perceived management support and individuals' behavioral support for change.

H2a: Change-efficacy positively mediates the relationship between perceived management support and compliance behavior

H2b: Change-efficacy positively mediates the relationship between perceived management support and championing behavior

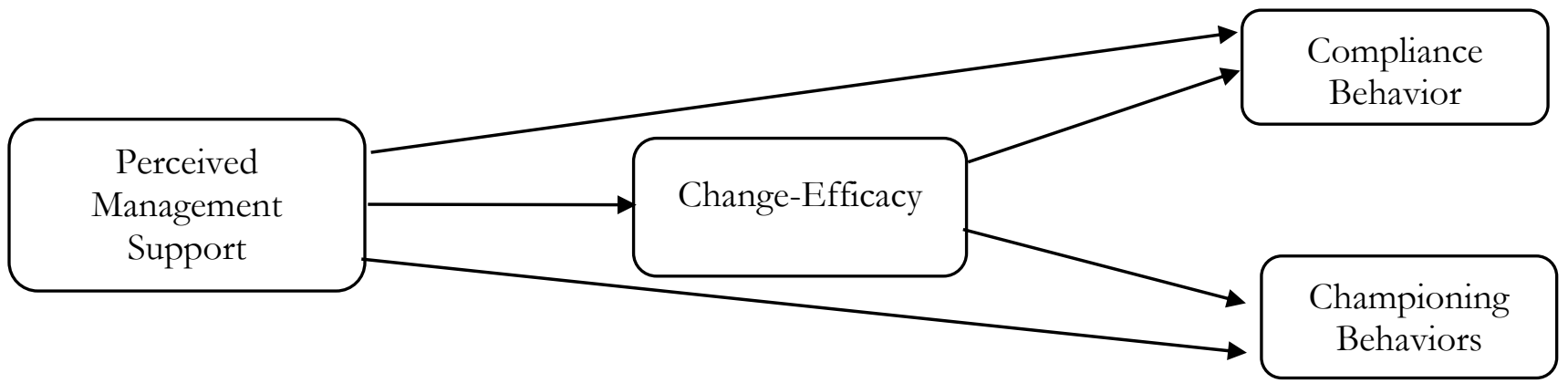

Figure 1 - Research Model

\section{Methods and Data Analysis}

The academic staff of six public sector universities located in two provinces (i.e., Punjab and Sindh) of Pakistan, where the population of this study from whom the data was drawn. The universities have been going through the quality enhancement initiatives undertaken by the higher education commission of Pakistan, such as implementing performance appraisal, tenure track status (TTS), research, and promotion policies. The data were randomly drawn from the pooled respondents of selected universities via a proportionate stratified random sampling technique. The sampling frame was generated based on the total number of academic staff in a representative university and its relative proportion in the study. Using Krejcie \& Morgan's (1970) sample determination criteria, the study distributed 545 questionnaires to targeted participants and retrieved 308 questionnaires in response, thus accounted for $57 \%$ of the response rate. After screening the data for multivariate outliers, 292 responses were found usable for data analysis. The 292 responses consider as sufficient to run data for multivariate analysis and estimations. It adequately satisfies the minimal responses threshold to carry out statistical analysis, as suggested by past scholars (Hair, Black, Babin \& Anderson, 2019; Kline, 2011). In corresponding responses, male participants constitute $73 \%$ of the sample. The participants with the age group 36 to 45 years relatively represent a larger proportion of 31\% than the rest. Likewise, $24 \%$ of the participants were of having experience ranging from 16 to 20 years. Around 55\% of them were Lecturers, and $49 \%$ possesses a Master's degree. 


\section{Measures}

Behavioral support for change was measured using nine items scale comprises of compliance (3) and championing behavior (6) developed by (Herscovitch \& Meyer, 2002). The scale was revised with few amendments wherein 'organization' was replaced with 'university' while 'change' was labeled a quality enhancement initiative by the university.' The sample item includes, "I speak positively about the quality enhancement initiative introduced by the university to colleagues." On the other hand, perceived management support was measured using a six items scale conceptualized by (Holt et al., 2007). The sample item includes, "Our senior leaders have encouraged all of us to embrace the quality enhancement initiative introduced by the university." Change-efficacy was measured using six items scale developed by (Holt et al., 2007). The sample item includes "I have the skills that are needed to make this change work." All four constructs were measured on a five-point Likert scale ranging from $1=$ Strongly disagree to $5=$ Strongly agree.

\section{Results}

Confirmatory factor analysis was carried out using AMOS 23 to assess the goodness of fit of the measurement model. For this purpose, we used three model fit indices (i.e., Comparative fit index, CFI: Goodness of fit Index GFI; Tucker-Lewis index, TLI: \& Root Mean Square Error of Approximation, RMSEA) to evaluate the validity of the proposed model. According to Hair et al. (2019), the fit values $\geq 0.95$ for CFI, GFI, and TLI, whereas less than 0.05 show a good fit model. Keeping in view, we compared and tested four alternative models (as determined by Bentler and Bonett, 1980), whereby the hypothesized model showed a better fit relative to the competing models $(\mathrm{CFI}=0.97$; GFI $=0.94$; TLI $=0.96$; RMSEA $=0.03 ; \mathrm{p}<0.000)$, which indicates that the study's research model has better aligned with the retrieved dataset (see Table 1). Moreover, the factor analysis results also showing the adequate validity of the working constructs as each item was loaded on its own measure (See Appendix for details).

Table 1: Model Fit indices

\begin{tabular}{|c|c|c|c|c|c|}
\hline Model Summary & CMIN/Df & CFI & GFI & TLI & RMSEA \\
\hline Model $1^{\text {a }}$ (One-factor solution) $^{a}$ & 4.73 & 0.63 & 0.71 & 0.59 & 0.13 \\
\hline Model $2^{\mathrm{b}}$ (Two-factor solution) $^{\mathrm{b}}$ & 3.84 & 0.73 & 0.74 & 0.70 & 0.10 \\
\hline Model $3^{c}$ (Three-factor solution) $^{c}$ & 2.67 & 0.84 & 0.82 & 0.82 & 0.08 \\
\hline Model $4^{\mathrm{d}}$ Original (Four-factor solution) ${ }^{\mathrm{d}}$ & 1.21 & 0.97 & 0.94 & 0.96 & 0.03 \\
\hline
\end{tabular}

a. One factor solution = all items loaded on Compliance Behavior

b. Two-factor solution= items loaded on Compliance Behavior and Perceived Management Support

c. Three-factor solution $=$ items loaded on Compliance Behavior, Change-Efficacy, and Perceived Management Support

d. Four-factor solution $=$ items loaded on Compliance Behavior, Change-Efficacy, Perceived Management Support, and Championing Behavior

Table 2 summarizes descriptive statistics, including zero-order correlation and reliability analysis of the functional constructs. The mean values of all factors were found above their relative midpoint ranging from $\mathrm{M}$ $=3.39$ to $\mathrm{M}=3.60$, thus indicated that the academic staff was generally in agreement with the statements inquired during the data collection. Moreover, the reliability analysis that has been assessed using Cronbach's alpha values also falls above the threshold level of 0.70 (as suggested by (Nunnally, 1978), ranging from 0.78 to 0.83 , thereby showing the scales used to measure the constructs are reliable. Also, all inter-construct correlations were found significant and pointed in the hypothesized direction. Specifically, the relationship between changeefficacy and compliance behavior was stronger $(r=0.45)$ than the rest. 
Table 2: Descriptive and Reliability Statistics

\begin{tabular}{l|llllll}
\hline \multicolumn{2}{l}{} & Mean & SD & $\mathbf{1}$ & $\mathbf{2}$ & $\mathbf{3}$ \\
\hline 1 & PMS & 3.41 & 0.73 & $(0.81)$ & & \\
2 & CEF & 3.49 & 0.76 & $0.32^{*}(0.78)$ & & \\
3 & COMP & 3.60 & 1.02 & $0.36^{*}$ & $0.45^{*}(0.82)$ & \\
4 & CHAMP & 3.39 & 0.80 & $0.37^{*}$ & $0.40^{*}$ & $0.37 *(0.83)$ \\
\hline
\end{tabular}

Values in parenthesis are Cronbach's alpha for reliability assessment

PMS: Perceived Management Support, CEF: Change-efficacy, COMP: Compliance Behavior, CHAMP: Championing

Behavior

Structural regression analysis (SRA) was used to test our hypotheses H1a, H1b. The hypotheses H1a and H1b concern with the positive effect of perceived management support on dimensions of behavioral support for change such as compliance and championing behavior. The result indicated that perceived management support has a significant impact on both compliance (COMP <--- PMS: $\beta=0.342$; SE $=0.075 ; p<.01$ ) as well as championing behavior (CHAMP <--- PMS: $\beta=0.286$; $S E=0.059 ; p<.01$ ) as shown in Table 3 and Figure 1. Thereby the result provided support for the corresponding hypothetical association.

Table 3: Structural Regression Analysis Results

\begin{tabular}{lllrrrr}
\hline & & & Estimate & S.E. & C.R. & P \\
\hline CEF & $<---$ & PMS & .322 & .057 & 5.662 & $* * *$ \\
COMP & $<--$ & PMS & .342 & .075 & 4.592 & $* * *$ \\
CHAMP & $<---$ & PMS & .286 & .059 & 4.828 & $* * *$ \\
COMP & $<---$ & CEF & .516 & .073 & 7.067 & $* * *$ \\
CHAMP & $<---$ & CEF & .348 & .058 & 6.002 & $* * *$ \\
\hline
\end{tabular}

$* * * \mathrm{p}<.01$

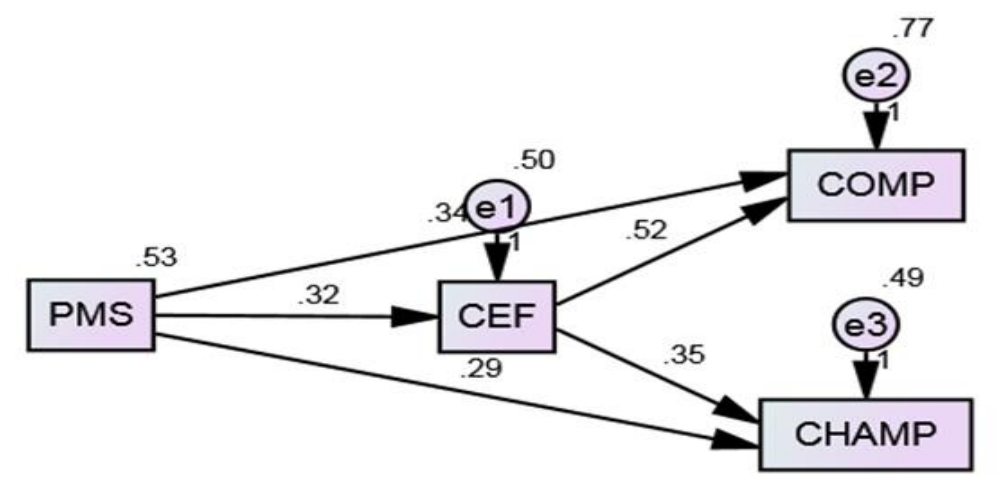

Figure 2 - Path Model

Moreover, the $\mathrm{H} 2 \mathrm{a}$ and $\mathrm{H} 2 \mathrm{~b}$ were poised to examine the mediating role of change-efficacy in translating the impact of perceived management support to the dimensions of behavioral support for change. As predicted, the result showed that the impact of perceived management support on compliance (COMP <--- CEF <--PMS: $\beta=0.17$; SE $=0.06 ; L L C I=0.09$; ULCI $=0.25$ ) and championing behavior $($ CHAMP $<---$ CEF <--PMS: $\beta=0.11 ; S E=0.03 ; L L C I=0.06 ; U L C I=0.17$ ) have indirectly been influenced by the presence of change-efficacy. Thus, providing support to both of our hypotheses (see Table 4). 


\section{Discussion and Conclusion}

The key objective of this study was to examine perceived management support during the time of organizational change to bring about one's behavioral support for change. It also aimed to identify the potential mechanism through which this association effectively transformed into behavioral support for change. The proposed framework was established and applied using the conservation of resources theory to explain the phenomenon under observation. The finding supported our hypotheses $\mathrm{H} 1 \mathrm{a}$ and $\mathrm{H} 1 \mathrm{~b}$ associated with a direct link of perceived management support and behavioral support for change. The results found parallel to the past studies whereby perceived management support found positively related to one's change-oriented outcomes (i.e. (Bakari et al., 2017; Haffar et al., 2019; Rafferty \& Minbashian, 2019).

Table 4: Mediation Analysis Results

\begin{tabular}{lcccc}
\hline & & \multicolumn{3}{c}{ Compliance } \\
\hline & Estimates & SE & Bower 95\% CI & Upper \\
Total effect of PMS on COMP & 0.51 & 0.08 & 0.35 & 0.66 \\
Direct Effect of PMS on COMP & 0.34 & 0.06 & 0.20 & 0.49 \\
Indirect Effect of PMS on COMP via CEF & 0.17 & 0.06 & 0.09 & 0.25 \\
& & & Championing \\
Total effect of PMS on CHAMP & 0.40 & 0.07 & 0.28 & 0.51 \\
Direct Effect of PMS on CHAMP & 0.29 & 0.06 & 0.17 & 0.40 \\
Indirect Effect of PMS on CHAMP via CEF & 0.11 & 0.03 & 0.06 & 0.17 \\
\hline
\end{tabular}

Note. BC $=$ bias corrected (5,000 bootstrapping samples); CI = confidence interval

Furthermore, the mediation results supported the already reported role of change-efficacy to spur changeoriented support behaviors. It has demonstrated that change-efficacy could also be an effective mechanism to facilitate the change of supportive behavior. Bayraktar and Jiménez (2020), in a recent study, also found changeefficacy as instrumental and lead to change-related outcomes such as commitment to change and intention to support change. It is also a significant determinant of change supportive behavior in a study conducted by (Shin et al., 2012). Moreover, the result also confirms self-efficacy as a critical resource, particularly in a demanding context such as during organizational change. It delineates; when individuals perceive that their top management provides ample support in response to future change, it likely makes them feel confident that they can accomplish the objectives set to implement change effectively. Which ultimately leads them to manifest either compliance or even go beyond to engage in championing behavior as revealed in this study. The findings thus are in line with the tenet of conservation of resources theory (COR), which suggests that resources, mainly self-efficacy serve as instrumental in the face of organizational change (Bayraktar \& Jimenez, 2019; Bayraktar \& Jiménez, 2020).

In brief, the study confirms the role of perceived management support as a context factor and a resource to stimulate change in supportive behaviors. It also provides support for change-efficacy as a personal resource to lead the change processes. The study thereby confirms that both context and person factors are empirically an excellent choice to incorporate to develop practical support for change mechanism as suggested by scholars (i.e. (Fugate \& Soenen, 2018; Oreg et al., 2011; Rafferty et al., 2013). The study thereby contributes to the literature on organizational change in two ways. First, it has responded to the call by past researchers (Fugate \& Soenen, 2018; Oreg et al., 2011; Rafferty et al., 2013) to examine both person and context factors to unveil the likely circumstances that promote or inhibit the supportive change orientation by the individuals. The study, in response, examined both aspects and provided empirical support to the subsequent call. Second, though past studies have demonstrated the impact of perceived management support and change-efficacy on one's 
commitment and support to change (Bakari et al., 2017; Rafferty \& Minbashian, 2019), however, examining change-efficacy as an intervening mechanism align with the conservation of resources theory (COR) perspective, particularly the active-passive behavioral activation (i.e., compliance and championing) towards change has been overlooked. Hence, this study sheds light on this view and empirically drawn support in this regard.

Moreover, the findings also revealed that academic staff was more involved in compliance-oriented behavior, which is categorized as a passive mode of support behavior, than championing behavior that has been tagged as an active form of behavior (see Kim, Hornung, \& Rousseau, 2011). The hypothetical associations even found stronger about compliance behavior than championing behavior. It suggests that the academic staff is more prone to comply with the subsequent change initiatives at the minimum acceptable level than act as champions to advocate change. The study, therefore, unfolds that employees' desirable response to change initiative could be promoted if the extent of support from top management and their level of efficacy regarding change increases. Conclusively the study provides scholars and practitioners a theoretical and empirical rationale for the underlying relationships and mechanism to develop the support for change, particularly under the university settings.

\section{Limitations and Future Research}

Despite the empirical contributions of the study, the findings of the study should be understood with certain limitations. First, the findings are based on the cross-sectional research design and single-source data that restrain our claim of causal relationships reported in this study. Although the framework was developed with extant literature review anchored with theoretical underpinning and results also provided support and confirmation of the propositions. However, more research has been needed, mainly via longitudinal or dyadic design, to validate the study findings. Second, the findings of the study are only subject to the academic staff of public sector universities. Therefore, further research is needed across cultures, sectors, and functional areas to confirm the generalizability of the model.

Funding: This research received no external funding.

Conflicts of Interest: The authors declare no conflict of interest.

\section{References}

Alessandri, G., Borgogni, L., \& Truxillo, D. M. (2015). Tracking job performance trajectories over time: A six-year longitudinal study. European Journal of Work and Organizational Psychology, 24(4), 560577.

Amiot, C. E., Terry, D. J., Jimmieson, N. L., \& Callan, V. J. (2006). A longitudinal investigation of coping processes during a merger: Implications for job satisfaction and organizational identification. Journal of Management, 32(4), 552-574.

Amis, J. M., \& Aïssaoui, R. (2013). Readiness for change: An institutional perspective. Journal of Change Management, 13(1), 69-95.

Armenakis, A. A., \& Bedeian, A. G. (1999). Organizational change: A review of theory and research in the 1990s. Journal of Management, 25(3), 293-315.

Armenakis, A. A., Bernerth, J. B., Pitts, J. P., \& Walker, H. J. (2007). Organizational change recipients' beliefs scale: Development of an assessment instrument. The Journal of Applied Behavioral Science, 43(4), 481-505.

Armenakis, A. A., \& Fredenberger, W. B. (1997). Organizational change readiness practices of business turnaround change agents. Knowledge and Process Management, 4(3), 143-152. 
Bakari, H., Hunjra, A. I., \& Niazi, G. S. K. (2017). How does authentic leadership influence planned organizational change? The role of employees' perceptions: Integration of theory of planned behavior and Lewin's three step model. Journal of Change Management, 17(2), 155-187.

Bandura, A. (1995). Self-efficacy in changing societies. Cambridge university press.

Bayraktar, S. (2019). How leaders cultivate support for change: Resource creation through justice and job security. The Journal of Applied Behavioral Science, 55(2), 213-234.

Bayraktar, S., \& Jimenez, A. (2019). Impact of Transformational Leadership on Positive Reactions to Change through Self-Efficacy. 2019(1), 12621. Academy of Management Briarcliff Manor, NY 10510.

Bayraktar, S., \& Jiménez, A. (2020). Self-efficacy as a resource: A moderated mediation model of transformational leadership, extent of change and reactions to change. Journal of Organizational Change Management.

Bentler, P. M., \& Bonett, D. G. (1980). Significance tests and goodness of fit in the analysis of covariance structures. Psychological Bulletin, 88(3), 588.

Bouckenooghe, D., M. Schwarz, G., \& Minbashian, A. (2015). Herscovitch and Meyer's three-component model of commitment to change: Meta-analytic findings. European Journal of Work and Organizational Psychology, 24(4), 578-595.

Burke, R. (2002). Hybrid recommender systems: Survey and experiments. User Modeling and User-Adapted Interaction, 12(4), 331-370.

Cascio, W. F., \& Aguinis, H. (2008). Research in industrial and organizational psychology from 1963 to 2007 : Changes, choices, and trends. Journal of Applied Psychology, 93(5), 1062.

Cinite, I., Duxbury, L. E., \& Higgins, C. (2009). Measurement of perceived organizational readiness for change in the public sector. British Journal of Management, 20(2), 265-277.

Coyle-Shapiro, J. A.-M. (1999). Employee participation and assessment of an organizational change intervention: A three-wave study of total quality management. The Journal of Applied Behavioral Science, 35(4), 439-456.

Day, K. M., Armenakis, A. A., Feild, H. S., \& Norris, D. R. (2012). Other organizations are doing it, why shouldn't we? A look at downsizing and organizational identity through an institutional theory lens. Journal of Change Management, 12(2), 165-188.

De Clercq, D., \& Belausteguigoitia, I. (2017). Mitigating the negative effect of perceived organizational politics on organizational citizenship behavior: Moderating roles of contextual and personal resources. Journal of Management \& Organization, 23(5), 689-708.

Falbe, C. M., \& Yukl, G. (1992). Consequences for managers of using single influence tactics and combinations of tactics. Academy of Management Journal, 35(3), 638-652.

Fugate, M., \& Soenen, G. (2018). Predictors and processes related to employees' change-related compliance and championing. Personnel Psychology, 71(1), 109-132.

Haffar, M., Al-Karaghouli, W., \& Ghoneim, A. (2014). An empirical investigation of the influence of organizational culture on individual readiness for change in Syrian manufacturing organizations. Journal of Organizational Change Management.

Haffar, M., Al-Karaghouli, W., Irani, Z., Djebarni, R., \& Gbadamosi, G. (2019). The influence of individual readiness for change dimensions on quality management implementation in Algerian manufacturing organisations. International Journal of Production Economics, 207, 247-260.

Hair, J. F., Black, W. C., Babin, B. J., Anderson, R. E., \& Tatham, R. L. (1998). Multivariate data analysis (Vol. 5). Prentice hall Upper Saddle River, NJ.

Herscovitch, L., \& Meyer, J. P. (2002). Commitment to organizational change: Extension of a threecomponent model. Journal of Applied Psychology, 87(3), 474.

Hiatt, J. (2006). ADKAR: a model for change in business, government, and our community. Prosci. 
Hobfoll, S. E. (1989). Conservation of resources: A new attempt at conceptualizing stress. American Psychologist, 44(3), 513.

Hobfoll, S. E. (2001). The influence of culture, community, and the nested-self in the stress process: Advancing conservation of resources theory. Applied Psychology, 50(3), 337-421.

Hobfoll, S. E., Halbesleben, J., Neveu, J.-P., \& Westman, M. (2018). Conservation of resources in the organizational context: The reality of resources and their consequences. Annual Review of Organizational Psychology and Organizational Behavior, 5, 103-128.

Holt, D. T., Armenakis, A. A., Feild, H. S., \& Harris, S. G. (2007). Readiness for organizational change: The systematic development of a scale. The Journal of Applied Behavioral Science, 43(2), 232-255.

Hughes, A., Galbraith, D., \& White, D. (2011). Perceived competence: A common core for self-efficacy and self-concept? Journal of Personality Assessment, 93(3), 278-289.

Huy, Q. N. (1999). Emotional capability, emotional intelligence, and radical change. Academy of Management Review, 24(2), 325-345.

Iqbal, A., \& Asrar-ul-Haq, M. (2018). Establishing relationship between TQM practices and employee performance: The mediating role of change readiness. International Journal of Production Economics, 203, 62-68.

Jansson, N. (2013). Organizational change as practice: A critical analysis. Journal of Organizational Change Management, 26(6), 1003-1019.

Jimmieson, N. L., Terry, D. J., \& Callan, V. J. (2004). A longitudinal study of employee adaptation to organizational change: The role of change-related information and change-related self-efficacy. Journal of Occupational Health Psychology, 9(1), 11.

Kavanagh, M. H., \& Ashkanasy, N. M. (2006). The impact of leadership and change management strategy on organizational culture and individual acceptance of change during a merger. British Journal of Management, 17(S1), S81-S103.

Kim, T. G., Hornung, S., \& Rousseau, D. M. (2011). Change-supportive employee behavior: Antecedents and the moderating role of time. Journal of Management, 37(6), 1664-1693.

Krejcie, R. V., \& Morgan, D. W. (1970). Determining sample size for research activities. Educational and Psychological Measurement, 30(3), 607-610.

Michel, A., Todnem, R., \& Burnes, B. (2013). The limitations of dispositional resistance in relation to organizational change. Management Decision, 51(4), 761-780.

Miraglia, M., Alessandri, G., \& Borgogni, L. (2015). Trajectory classes of job performance. Career Development International.

Neves, P. (2009). Readiness for change: Contributions for employee's level of individual change and turnover intentions. Journal of Change Management, 9(2), 215-231.

Ng, T. W., \& Lucianetti, L. (2016). Within-individual increases in innovative behavior and creative, persuasion, and change self-efficacy over time: A social-cognitive theory perspective. Journal of Applied Psychology, 101(1), 14.

Nunnally, J. C. (1978). Psychometric Theory: 2d Ed. McGraw-Hill.

Oreg, S., Bartunek, J. M., Lee, G., \& Do, B. (2018). An affect-based model of recipients' responses to organizational change events. Academy of Management Review, 43(1), 65-86.

Oreg, S., Vakola, M., \& Armenakis, A. (2011). Change recipients' reactions to organizational change: A 60 year review of quantitative studies. The Journal of Applied Behavioral Science, 47(4), 461-524.

Rafferty, A. E., Jimmieson, N. L., \& Armenakis, A. A. (2013). Change readiness: A multilevel review. Journal of Management, 39(1), 110-135.

Rafferty, A. E., \& Minbashian, A. (2019). Cognitive beliefs and positive emotions about change: Relationships with employee change readiness and change-supportive behaviors. Human Relations, 72(10), 16231650 . 
Rafferty, A. E., \& Restubog, S. L. (2017). Why do employees' perceptions of their organization's change history matter? The role of change appraisals. Human Resource Management, 56(3), 533-550.

Schreyögg, G., \& Sydow, J. (2010). Crossroads-Organizing for fluidity? Dilemmas of new organizational forms. Organization Science, 21(6), 1251-1262.

Sharma, N., Herrnschmidt, J., Claes, V., Bachnick, S., De Geest, S., Simon, M., \& MatchRN-Study Group. (2018). Organizational readiness for implementing change in acute care hospitals: An analysis of a cross-sectional, multicentre study. Journal of Advanced Nursing, 74(12), 2798-2808.

Shin, J., Taylor, M. S., \& Seo, M.-G. (2012). Resources for change: The relationships of organizational inducements and psychological resilience to employees' attitudes and behaviors toward organizational change. Academy of Management Journal, 55(3), 727-748.

Stouten, J., Rousseau, D. M., \& De Cremer, D. (2018). Successful organizational change: Integrating the management practice and scholarly literatures. Academy of Management Annals, 12(2), 752-788.

Strauss, K., \& Parker, S. K. (2018). Intervening to enhance proactivity in organizations: Improving the present or changing the future. Journal of Management, 44(3), 1250-1278.

Tims, M., Bakker, A. B., \& Derks, D. (2014). Daily job crafting and the self-efficacy-performance relationship. Journal of Managerial Psychology.

Tomprou, M., Nikolaou, I., \& Vakola, M. (2012). Experiencing organizational change in Greece: The framework of psychological contract. The International Journal of Human Resource Management, 23(2), 385-405.

Vakola, M. (2014). What's in there for me? Individual readiness to change and the perceived impact of organizational change. Leadership \& Organization Development Journal.

van den Heuvel, M., Demerouti, E., \& Bakker, A. B. (2014). How psychological resources facilitate adaptation to organizational change. European Journal of Work and Organizational Psychology, 23(6), 847-858.

Wanberg, C. R., \& Banas, J. T. (2000). Predictors and outcomes of openness to changes in a reorganizing workplace. Journal of Applied Psychology, 85(1), 132.

Zhao, H. H., Seibert, S. E., Taylor, M. S., Lee, C., \& Lam, W. (2016). Not even the past: The joint influence of former leader and new leader during leader succession in the midst of organizational change. Journal of Applied Psychology, 101(12), 1730.

Zhou, Q., Martinez, L. F., Ferreira, A. I., \& Rodrigues, P. (2016). Supervisor support, role ambiguity and productivity associated with presenteeism: A longitudinal study. Journal of Business Research, 69(9), 3380-3387. 


\section{Appendix}

Factor Analysis (Principal Component Analysis) of the Study Variables

Table 5: Factor Analysis

KMO and Bartlett's Test

Kaiser-Meyer-Olkin Measure of Sampling Adequacy.

Bartlett's Test of Sphericity

Approx. Chi-Square

2091.386

df

Sig.

\begin{tabular}{|c|c|c|c|c|}
\hline & \multicolumn{4}{|c|}{ Component } \\
\hline & 1 & 2 & 3 & 4 \\
\hline CHAMP_3 & .736 & & & \\
\hline CHAMP_5 & .729 & & & \\
\hline CHAMP_1 & .724 & & & \\
\hline CHAMP_4 & .718 & & & \\
\hline CHAMP_6 & .684 & & & \\
\hline CHAMP_2 & .637 & & & \\
\hline CEF_1 & & .777 & & \\
\hline CEF_4 & & .719 & & \\
\hline CEF_5 & & .691 & & \\
\hline CEF_6 & & .658 & & \\
\hline CEF_3 & & .637 & & \\
\hline CEF_2 & & .619 & & \\
\hline PMS_1 & & & .717 & \\
\hline PMS_2 & & & .701 & \\
\hline PMS_3 & & & .686 & \\
\hline PMS_5 & & & .665 & \\
\hline PMS_4 & & & .658 & \\
\hline PMS_6 & & & .539 & \\
\hline COMP_3 & & & & .836 \\
\hline COMP_2 & & & & .784 \\
\hline COMP_1 & & & & .782 \\
\hline \multicolumn{5}{|c|}{$\begin{array}{l}\text { Extraction Method: Principal Component Analysis. } \\
\text { Rotation Method: Varimax with Kaiser Normalization. }\end{array}$} \\
\hline a. Rotation & in 5 & & & \\
\hline
\end{tabular}

